\title{
Professoras itinerantes do ensino superior: condições de saúde e jornada dupla de trabalho
}

\author{
Itinerant teachers of higher education: health conditions and double working hours \\ Docentes itinerantes de educación superior: condiciones de salud y doble jornada
}

Simone Samires dos Reis ${ }^{1 *}$, Saulo Daniel Mendes Cunha ${ }^{1}$.

\begin{abstract}
RESUMO
Objetivo: Analisar a repercussão da dupla jornada nas condições de vida, saúde e no trabalho de professoras universitárias de uma universidade pública do Norte de Minas. Métodos: A presente pesquisa foi desenvolvida por meio da abordagem qualitativa. Participaram deste estudo sete professoras. A coleta dos dados foi realizada nos meses de fevereiro e março de 2020 e, para a entrevista, foi utilizado um roteiro semiestruturado. Já para o registro das entrevistas, foi utilizado um gravador da marca Samsung®, a fim de capturá-las para análise de todas as informações fornecidas pelos participantes. Resultados: A pesquisa apresentou resultados significativos, mostrando a realidade em que esta instituição pesquisada se encontra atualmente. As principais queixas das professoras foram relacionadas à falta de estrutura, espaços de aula para disciplinas com caráter prático, o que dificulta o processo de ensino-aprendizado dos seus alunos e da dupla jornada de trabalho. Conclusão: Este trabalho nos chama atenção uma vez que a docente precisa de tempo para o lazer e tempo para cuidar da saúde (física, psicológica e mental), destacando ainda mais a importância de políticas públicas para a promoção e prevenção da saúde desta classe de trabalhadoras que trabalham em dupla jornada.
\end{abstract}

Palavras-chave: Mulheres, Docência, Condições de trabalho.

\begin{abstract}
Objective: To analyze the impact of the double shift on the conditions of life, health and work of university professors at a public university in the North of Minas Gerais. Methods: This research was developed using the qualitative approach. Seven teachers participated in this study. Data collection was carried out in February and March 2020 and, for the interview, a semi-structured script was used. As for the record of the interviews, a Samsung ${ }^{\circledR}$ recorder was used in order to capture them for analysis of all the information provided by the participants. Results: The research presented significant results, showing the reality in which, this researched institution is currently located. The main complaints of the teachers were related to the lack of structure, classroom spaces for subjects with a practical character, which hinders the teaching-learning process of their students and the double workday. Conclusion: This work calls our attention since the teacher needs time for leisure and time to take care of health (physical, psychological and mental), further highlighting the importance of public policies for the promotion and prevention of health of this class of workers who work double shifts.
\end{abstract}

Key words: Women, Teaching, Working conditions.

\section{RESUMEN}

Objetivo: Analizar el impacto del doble turno en las condiciones de vida, salud y trabajo de los profesores universitarios de una universidad pública del Norte de Minas Gerais. Métodos: Esta investigación se desarrolló utilizando el enfoque cualitativo. Siete profesores participaron en este estudio. La recolección de datos se realizó en febrero y marzo de 2020 y, para la entrevista, se utilizó un guión semiestructurado. En cuanto al registro de las entrevistas, se utilizó una grabadora Samsung® con el fin de capturarlas para el análisis de toda la información proporcionada por los participantes. Resultados: La investigación presentó resultados significativos, mostrando la realidad en la que se encuentra actualmente esta institución investigada. Las principales quejas de los docentes se relacionaron con la falta de estructura, espacios de

1 Universidade Estadual de Montes Claros (UNIMONTES), Montes Claros - MG.

*E-mail:998801307s@gmail.com.br

SUBMETIDO EM: 10/2020 
aula para asignaturas con carácter práctico, lo que dificulta el proceso de enseñanza-aprendizaje de sus alumnos y la doble jornada laboral. Conclusión: Este trabajo llama nuestra atención ya que el docente necesita tiempo para el esparcimiento y tiempo para cuidar la salud (física, psicológica y mental), resaltando aún más la importancia de las políticas públicas para la promoción y prevención de la salud de esta clase de trabajadores que trabajan a doble jornada.

Palabras clave: Mujeres, Enseñanza, Condiciones de trabajo.

\section{INTRODUÇÃO}

O mundo vive em constantes transformações e inovações, por isso é sempre importante a busca pelas mudanças e atualizações, visando acompanhar os novos paradigmas curriculares da educação. Diante dessas inovações, é necessário que o docente esteja disposto a sempre reinventar-se e pesquisar novos métodos de ensino-aprendizagem. Por outro lado, Santos CC, et al. (2018), explica que os professores são cobrados por novas competências, novos focos de preocupação e novas atividades, o que instaura uma intensificação na carga horária de trabalho docente.

No contexto da docência, destaca-se a questão de gênero. No cenário educativo, Vianna CP (2001) pontua que ao longo do século $X X$ o magistério tornou-se eminentemente de caráter feminino, em especial a Educação Básica; havendo, de maneira geral, uma predominância das mulheres na profissão docente. $O$ trabalho tornou-se o meio pelo qual as mulheres adquiriram a chave para a liberdade concedida pela emancipação financeira, porém tal liberdade é carregada de densas dificuldades que tornam as desigualdades estruturais entre homens e mulheres no mercado de trabalho mais notórias. Essas desigualdades revelam que existe uma liberdade de escolha por parte dos homens que podem apenas trabalhar sem se preocupar com as tarefas domésticas.

Sá TT e Neto FRA (2016) relatam que a profissão docente é bastante antiga, iniciada com a necessidade dos homens em organizar, resguardar, preservar e transmitir o conhecimento adquirido ao longo de suas gerações como forma de sua afirmação e permanência social. Durante muito tempo, a profissão de professor era vista como algo meramente vocacional ou mesmo um dom, sendo os padres e sacerdotes os primeiros professores a exercer o ofício, e entendida como uma tarefa relativamente simples, sem a necessidade de maiores formações na área. Antigamente, o trabalho docente era destinado apenas aos homens. Com o surgimento da escola normal, a primeira escola formada por professores, as mulheres foram aceitas e acabaram dominando a profissão docente, de uma maneira geral.

A inserção da mulher no mercado de trabalho sempre foi muito discutida e questionada, já que o enraizamento numa construção social machista, ainda questiona e impede a ascensão de muitas mulheres no mercado de trabalho. Costa FA (2018) aponta que na origem da formação da sociedade capitalista, o homem teria como principal papel garantir o sustento fora do lar, enquanto a mulher cuidaria da administração da casa e das tarefas domésticas. Com o passar do tempo, a mulher vem conquistando o seu espaço no mercado de trabalho, e alguns estereótipos passam a ser combatidos e modificados.

Nesta perspectiva, nos tempos atuais, as mulheres vêm lutando por espaços que antes eram impossíveis de se conquistar, como também lutando por uma igualdade social e salarial, no mercado de trabalho, compatível com as conquistas do gênero masculino. Para Parra E, et al. (2014), a fase da evolução social presenciada na nova identidade feminina nos faz refletir que o trabalho não gera a destruição e desistência da mulher frente à concorrência masculina, mas apresenta uma grande surpresa através dos seus resultados positivos, mostrando um novo modelo de força feminina. A mulher passa o dia no trabalho lutando para evoluir na sua carreira, ao mesmo tempo em que pensa nas tarefas domésticas, culpando-se de não conseguir fazer tudo da forma como planeja, querendo fazer tudo ao mesmo tempo, e, por conseguinte, acaba desrespeitando os limites do seu corpo, esquecendo-se de si mesma e gerando estresse e sobrecarga de tarefas.

Sob esse ponto de vista, notamos que, mediante os avanços industriais e o aumento de emprego, a mulher passou a ter mais espaço no mercado de trabalho (incluindo aí o trabalho na docência), gerando uma jornada de trabalho muito mais extensa (soma-se ao mercado de trabalho, as atividades laborais em casa - em muitos 
casos, o cuidado com filhos e com marido, por exemplo). Percebe-se, então, que a mulher além de exercer o papel de mãe, dona de casa, esposa, passou também a ter seu lugar no mercado de trabalho. Contudo, a sua carga horária de trabalho, quase sempre, é superior em relação aos homens, chegando a 75 (setenta e cinco) horas semanais (CALIL LES, 2007).

Diante do exposto, vamos discutir a atuação da mulher/professora itinerante (que viaja para ministrar aulas noutra cidade), enquadrada na docência do ensino superior, e os possíveis reflexos na saúde dessas trabalhadoras; já que desempenham papéis sociais adjuntos (mães, esposas, professoras), podendo apresentar uma jornada exaustiva ao longo do tempo de trabalho e afetar de maneira considerável a saúde biopsicossocial (MEIRA TRM, et al., 2014).

Sendo assim, o objetivo do estudo é analisar a repercussão da dupla jornada de trabalho docente feminino nas condições de vida, saúde e no trabalho, através da compreensão das percepções das professoras (do ensino superior, de uma instituição pública do norte de Minas Gerais-MG) sobre a saúde biopsicossocial e a relação com as condições de trabalho.

\section{MÉTODOS}

Trata-se de uma pesquisa de campo, de caráter qualitativo. Os sujeitos do estudo foram professoras/docentes do sexo feminino, atuantes numa Universidade Pública do norte de Minas Gerais.

A população do estudo foi composta por sete professoras. Para inclusão na pesquisa, as participantes deveriam ser profissionais da educação do sexo feminino, atuantes no ensino superior desta referida instituição, que viajam todos (ou alguns) dias para uma determinada cidade do interior de Minas Gerais, para ministrarem aula naquele campus, com formação em qualquer área do conhecimento, e que aceitassem participar da pesquisa através da assinatura do termo de consentimento livre e esclarecido.

A coleta dos dados foi realizada nos meses de fevereiro e março de 2020, buscando atingir o objetivo proposto. Foi utilizado como instrumento de coleta de dados a entrevista individual com roteiro semiestruturado. Para o registro das entrevistas, foi utilizado um gravador da marca Samsung® a fim de capturar os áudios das participantes para posterior análise dos dados.

Os dados foram analisados por meio da técnica de análise de categorias (MINAYO MCS, 2008). O conteúdo coletado na entrevista semiestruturada foi transcrito na íntegra e, após transcrição e leitura dos relatos, foi utilizado o método da categorização dos dados proposta por Minayo MCS (2008) que postula: "trabalhar com categorias significa agrupar elementos, ideias ou expressões em torno de um conceito capaz de abranger tudo isso".

A fim de se garantir o anonimato das entrevistadas, foram utilizados números de identificação para cada professora, as quais foram identificadas com os códigos (P1, P2, P3, P4, P5, P6, P7 sendo "P" de professoras, e o número a frente de acordo com a ordem em que foram entrevistadas).

Por se tratar de uma pesquisa envolvendo seres humanos, o projeto foi submetido ao Conselho de Ética em Pesquisa da Universidade Estadual de Montes Claros (Unimontes), sendo aprovado mediante Parecer Consubstanciado no 3.719 .807 do dia 23/10/2019. O estudo respeitou os princípios e as exigências formais contidas em normas que regulam as pesquisas envolvendo seres humanos. $O$ aceite da participação se deu através da assinatura do Termo de Consentimento Livre e Esclarecido.

\section{RESULTADOS E DISCUSSÃO}

A entrevista foi realizada com sete professoras/docentes do sexo feminino atuantes numa Universidade Pública do norte de Minas Gerais, que viajam todos (ou alguns) os dias para a cidade/campi no interior de Minas Gerais, e que aceitaram participar e assinar o termo de consentimento livre e esclarecido. Com a análise dos dados, foi possível identificar quatro categorias emergentes: "Relação entre mulher/professora, condições de trabalho e saúde"; "Atividade desenvolvida no trabalho docente que afetam a saúde"; "A conciliação do trabalho com as atividades da prática de lazer", "Condição de trabalho na Universidade e a interferência na sala de aula". 


\section{Ser professora: relação entre condições de trabalho e saúde}

Segundo Meira TRM, et al. (2014), a desvalorização profissional, a sobrecarga de trabalho e a baixa remuneração, enfrentados pelo professor, favorecem uma condição que pode contribuir na produção de evento adverso à saúde deste profissional, em resposta às condições enfrentadas na profissão.

Seguem abaixo, alguns relatos das professoras sobre a relação "condições de trabalho e saúde":

"Eu acho que não exista muita relação entre o fato de ser mulher, das condições de trabalho na docência, e a questão da saúde não. [...] eu acho que isso depende muito da pessoa em si, da forma como ela vive, da vida que ela tem, do gostar de ser docente, de ter prazer para trabalhar com isso" (P4).

"Na verdade, a gente esquece um pouco da saúde, no meu caso, o tempo é bem curto [...] eu procuro ir ao clínico uma vez ao ano pelo motivo de ser hipertensa (P1).

Para a professora $\mathrm{P} 4$, a docência e as condições de trabalho parecem não afetar a sua saúde. $\mathrm{E}$ isto parece estar relacionado com a maneira como ela leva a vida, encara a vida. De acordo com Souza NA e Leite MP (2011), discussões e estudos relacionados a buscar relações entre trabalho, saúde/doença possuem já uma longa história, das ciências sociais e da saúde em suas distintas especialidades, com várias explicações distintas buscando uma melhoria na docência. Apesar de haver prazer em ser docente, esta profissão é carregada de problemas complexos e pode sim, às vezes, afetar a saúde da professora, apesar de a professora P4 relatar que isso depende muito de cada pessoa (GASPARINI SM, et al., 2005).

Já a professora P1 parece queixar-se da falta de tempo para cuidar da própria saúde. Neste sentido, Hoffmann C, et al. (2017) mostra a diferença dos indicadores críticos de adoecimento no trabalho entre homens e mulheres docentes. Seu estudo revela que as mulheres apresentaram maior vulnerabilidade e maior esgotamento físico em relação aos homens. Mesmo com várias mudanças da sociedade em relação à inclusão da mulher no mercado de trabalho, o cuidado com a família ainda fica sob a responsabilidade da mulher podendo aumentar ainda mais a sua sobrecarga. A professora P1 relata uma sobrecarga de funções; e parece ter cuidado com a saúde, pelo aparecimento de uma doença (Hipertensão arterial) faz exames uma vez por ano.

Neste sentido, entendemos que de fato o cotidiano docente, pode, de certa forma, impactar (ou não) a vida de cada professora, já que os sentimentos e acometimentos em relação à saúde podem ser distintos. Neves MYR e Silva ES (2006) apontam um paralelo entre o prazer e o desprazer de ser docente, no qual relatam que as principais queixas das professoras é a falta de reconhecimento social, desvalorização do ensino público, salários baixos e a falta de compromisso político com a educação. Neste sentido, algumas professoras buscam outro emprego, a fim de complementar o orçamento familiar, o que, em geral, compromete ainda mais a qualidade de seu desempenho e incide na qualidade de vida e saúde. Por outro lado, o mesmo autor revela um prazer por parte dos professores ao criar uma relação afetiva com os alunos, que pode ser um ponto amenizador deste impacto na saúde do docente.

\section{Atividades desenvolvidas no trabalho docente que afetam a saúde}

Ao logo dos anos foram desenvolvidos vários trabalhos e pesquisas relacionados com o trabalho docente e saúde, mostrando bases e resultados e provando o adoecimento dos docentes no ambiente escolar. A baixa remuneração, a longa jornada de trabalho, na qual o professor trabalha em vários turnos, pode resultar em vários efeitos perversos: desgaste físico e psicológico e até mesmo no abandono da profissão em consequência da carga de trabalho excessiva (BARROS CAFS e GRADELA A, 2017).

Neste cenário, percebemos que a docência, na atualidade, é caracterizada como desgastante. Fatores como: salários insuficientes, jornadas exaustivas, muito tempo fora dos seus lares e alto custo da condução para locomoção de trabalho em algumas cidades, podem levar a uma defasagem quanto à produção do trabalho docente, com repercussões e abalos na saúde e na vida pessoal (ZIBETTI MLT e PEREIRA SR, 2010). Neste sentido, os possíveis resultados em relação à saúde destas trabalhadoras são: problemas de estresse, insônia, cansaço físico e emocional. 
Seguem abaixo, alguns relatos das professoras sobre a relação "Atividades desenvolvidas no trabalho docente que afetam a saúde":

"Meu maior desafio na educação e lidar com alunos, mais assim desde que eu consiga controlar meus níveis de estresse, está tranquilo" (P4).

"No trabalho nenhuma atividade atrapalha minha saúde, mas na locomoção para o trabalho eu vejo que sim. Sinto muitas dores no corpo" (P5).

A entrevistada P4 parece perceber na docência uma atividade extremamente desgastante, já que a lida com os alunos é algo que talvez seja penoso para ela. De acordo Freitas GRD, et al. (2018), o trabalho docente pode expor os professores a estímulos estressores, principalmente no trato diário das relações humanas (relação professor e alunos) podendo desencadear quadros de ansiedade e estresse, impactando a saúde mental das professoras. Problemas como indisciplina, descaso com a prática pedagógica e apatia podem sim influenciar na saúde mental das docentes.

De acordo com a entrevista de P5, o que afeta sua saúde são as condições de locomoção, pois a mesma viaja todos os dias para outra cidade e sente dores no corpo. Sanchez HM, et al. (2019) relata que há muitos professores que apresentam dores nas pernas, perda de voz e dores nas costas devido à posição adotada por eles no ambiente de trabalho, desencadeando uma fadiga física e mental. Somado a estas posturas viciosas da carreira docente, esta professora ainda viaja em torno de 06 horas por dia para ministrar aula numa outra cidade, aonde a universidade apresenta um campus. Toda esta sobrecarga pode afetar diretamente a estrutura musculoesquelética desta professora, e com o tempo, pode desenvolver quadros clínicos patológicos.

As docentes, embora satisfeitas com seu trabalho, parecem apresentar algum tipo de problema de saúde, sejam eles, estresse ou dores musculares. Isso revela a importância da criação de políticas públicas para a prevenção de doenças e promoção da saúde de professores dentro e fora do ambiente de trabalho. É necessário também melhorias na formação dos professores, no ambiente de trabalho e na remuneração (BARROS CAFS e GRADELA A, 2017).

\section{A conciliação do trabalho com as atividades da prática de lazer}

O lazer é algo indispensável na vida de qualquer ser humano. Quando o homem ou mulher envolve-se em atividades desse tipo a sensação é de conforto, realização e liberdade. Para Godtsfriedt J (2010), o lazer está contido em toda atividade que a pessoa executa em seu tempo disponível, que visa sempre a diversão, descontração e convívio social. Essas atividades podem proporcionar para o indivíduo uma sensação de bemestar e contribuir para o desenvolvimento social do ser humano e construção de novas amizades, além de desenvolver a confiança em si mesmo. O lazer aparece fora do horário laboral ou em período de férias.

Conforme Sanchez HM, et al. (2019), a prática de atividade física desempenha um papel importante para o alívio do estresse do dia a dia, para uma boa qualidade de vida, melhora no sono, enfim, de maneira geral o exercício físico é um forte aliado na melhoria da saúde e na promoção e prevenção de doenças. Além disso pode ser considerado também uma forma de lazer.

Seguem abaixo, alguns relatos das professoras sobre a "conciliação do trabalho com as atividades da prática de lazer":

\section{"[...] com muito esforço tenho conseguido fazer minha prática de lazer" (P4).}

“[...] ultimamente não estou conseguindo fazer essa conciliação não, porque estou com excesso de trabalho recentemente. Mas sempre que posso tento fazer o lazer, até mesmo porque tenho meu filho que precisa dessa parte, mas está sendo um pouco difícil" (P6).

De acordo com o relato da professora $\mathrm{P} 4$, parece que ela consegue ter tempo para o lazer, conseguindo se esforçar entre a docência e o seu tempo livre. O que chama atenção na fala desta professora é o termo "esforço", já que ela parece ter que se esforçar para dar conta de ter tempo livre e aproveitá-lo. De acordo 
com Oliveira MM, et al. (2015), a maioria das docentes de ensino superior nas universidades públicas exercem a função em dedicação exclusiva a esse emprego. Muitas delas ainda possuem outras atividades remuneradas para complementação de sua renda, sendo estas atividades até mesmo de docência em outra instituição privada de ensino, alternando suas atividades em cada uma, em diferentes dias da semana. Restando, desta forma, muitas vezes, pouco tempo livre para lazer.

Um aspecto importante observado em relação à professora (P6) foi a falta de tempo para a prática de atividades de lazer. Essa professora relata o fato de a sobrecarga de trabalho e a maternidade recente (uma vez que teve o primeiro filho) terem extinguido o tempo para a prática do seu lazer. Pereira MS (2016) explica que é direito do professor utilizar um tempo livre sem obrigação ou interesse econômico. Entretanto, na vida real da maioria dos docentes, o que se percebe é a sobrecarga de trabalho. E essa sobrecarga é ampliada quando a mulher se depara com as atribuições da maternidade. Desta forma, o aproveitamento do tempo do lazer, para melhoria da saúde do profissional, é quase inexistente, o que pode repercutir em problemas emocionais e redução do prazer do exercício da profissão docente.

Portanto, é necessário que ao investir na carreira docente, considerar-se que os professores, assim como qualquer outra classe de trabalhadores, precisam desfrutar do seu tempo livre para realizar suas atividades, para além da sala de aula, tornando-se melhores docentes e melhores seres humanos.

\section{Condição de trabalho na Universidade e a interferência na sala de aula}

As condições da infraestrutura das universidades públicas compõem um dos fatores que os professores de universidades mais queixam. Algumas universidades não disponibilizam de materiais, salas adequadas para aulas (teóricas e práticas), laboratórios equipados e adequados, e até mesmo de transporte adequado aos alunos e professores que precisam deslocar-se para outras cidades para compor este cenário educativo (docentes e estudantes). Sá JS e Corrêa FO (2017) explicam que a infraestrutura escolar pode exercer uma influência na qualidade da educação, ou seja, que prédios e instalações adequados podem, possivelmente, melhorar o desempenho dos alunos nas aulas.

Segue a baixo alguns relatos de professoras sobre a "Condição de trabalho na Universidade e a interferência na sala de aula":

"Interfere demais negativamente, eu trabalho com práticas pedagógicas (...), eu trabalho com uma disciplina de caráter prático, enfim, eu trabalho com disciplinas que algumas delas são extremamente práticas e o campus não tem espaço para as aulas de Educação Física, não existe espaço próprio para isso..." (P4).

"As condições oferecidas pela instituição que eu trabalho, falta um pouco com infraestrutura, minha disciplina tem muita parte prática e nessa instituição eu não tenho como realizar essas práticas, o que prejudica bastante o desenvolvimento das minhas aulas" (P6).

De acordo com o relato da professora P4, há, aparentemente, reclamações sobre a falta de locais adequados para ministrar as aulas práticas. É muito complexo entender o ensino de disciplinas de caráter predominantemente prático sem espaços e materiais adequados. Isto pode impactar diretamente no processo de ensino- aprendizagem no contexto da docência. Como relatam Silva AF e Souza ALL (2013), os professores, pela falta de recursos no setor público, se tornaram preparados para essas dificuldades apresentadas no trabalho escolar, entretanto, é essencial uma atenção das políticas públicas para investimento em espaços de ensino adequados e materiais disponíveis para que as aulas sejam potencializadas. As professoras não devem se acostumar com este cenário.

No discurso da professora $\mathrm{P} 6$, a instituição parece não oferecer espaço adequado para as aulas práticas prejudicando, assim, o desenvolvimento das aulas. Para Damazio MS e Silva MFP (2008), a ausência e a pouca qualidade de espaço físico e de instalações adequadas para as aulas podem ser compreendidas sob dois aspectos: a não valorização social desta disciplina e o descaso das autoridades para com a educação destinada às camadas populares. 
Nesse sentido, no Brasil, o que se pode analisar a partir dessas questões é que cada vez mais o trabalho do professor, especialmente das universidades públicas, tem se expandido para além do campo pedagógico, e esse profissional, por sua vez, vem vivenciando um processo de intensificação e precarização de seu trabalho. A escola não é um lugar apenas para estudar, mas para socializar, fazer política, discutir e aprender com os colegas de trabalho, cabe, portanto, aos gestores conduzir, liderar e agir de maneira que a convivência de todos aconteça da melhor maneira possível.

\section{CONCLUSÃO}

A pesquisa apresentou resultados significativos, como a realidade na qual as docentes se encontram atualmente. As principais queixas foram relacionadas à falta de estrutura das salas de aula, falta de materiais didáticos e falta de espaços para disciplinas com caráter prático. Em relação à dupla jornada de trabalho, algumas professoras disseram não apresentar relação o fato de ser mulher e professora ao mesmo tempo. Entretanto, outras professoras demostraram sobrecarga de trabalho, com os afazeres domésticos, cuidados da família, com a viagem (para trabalho na universidade) e com o trabalho docente (em casa). Este estudo revela que a docente precisa de tempo para o lazer e tempo para cuidar da saúde, destacando ainda, a importância de políticas públicas para a promoção e prevenção da saúde das mesmas.

\section{REFERÊNCIAS}

1. BARROS CAFS, GRADELA A. Condições de trabalho docente na rede pública de ensino: os principais fatores determinantes para o afastamento da atividade docente. REVASF, 2017; 7(13): 75-87.

2. CALIL LES. Direito do trabalho da mulher: a questão da igualdade jurídica ante a desigualdade fática. São Paulo, 2007.

3. COSTA FA. Mulher, trabalho e família: os impactos do trabalho na subjetividade da mulher e em suas relações familiares. Pretextos-Revista da Graduação em Psicologia da PUC Minas, 2018; 3(6): 434-452.

4. DAMAZIO MS, SILVA MFP. O ensino da educação física e o espaço físico em questão. Pensar a Prática, 2008; 11(2): 189-196.

5. FREITAS GRD, et al. Estresse, ansiedade e qualidade de vida em professores: efeitos do relaxamento progressivo. Psicologia Escolar e Educacional, 2018; 22(2): 319-326.

6. GASPARINI SM, et al. O professor, as condições de trabalho e os efeitos sobre sua saúde. Educação e Pesquisa, 2005; 31(2): 189-199.

7. GODTSFRIEDT J. Prática do lazer: uma revisão de conceitos, barreiras e facilitadores. Efdeportes Revista Digital, 2010.

8. HOFFMANN C, et al. Psicodinâmica do trabalho e riscos de adoecimento no magistério superior. Estudos Avançados, 2017; $31(91):$ 257-276.

9. MEIRA TRM, et al. Percepções de professores sobre trabalho docente e repercussões sobre sua saúde. Revista Brasileira em Promoção da Saúde, 2014; 27(2): 276-282.

10. MINAYO MCS. O desafio do conhecimento: Pesquisa qualitativa em saúde. 1nd ed. São Paulo: HUCITEC, 2008.

11. NEVES MYR, SILVA ES. A dor e a delícia de ser (estar) professora: trabalho docente e saúde mental. Estudos e Pesquisas em Psicologia, 2006; 6(1): 63-75.

12. OLIVEIRA MM, et al. Conciliando a carreira docente e família: um estudo comparativo entre professoras de instituição de ensino superior pública e privada. Oikos: Família e Sociedade em Debate, 2015; 26(1): 69-102.

13. PARRA E, et al. A Doença do Século: Estresse Ocupacional na Mulher Moderna. 2015.

14. PEREIRA MS. O direito ao lazer do professor de ensino superior. RFD-Revista da Faculdade de Direito da UERJ, 2016; (30): 55-76.

15. SÁ JS, CORRÊA FO. Infraestrutura escolar e espaço físico em educação: o estado da arte. Cadernos de Pesquisa, $2017 ; 47(164) ; 386-413$.

16. SÁ TT, NETO FRA. A docência no Brasil: história, obstáculos e perspectivas de formação e profissionalização no século XXI. Revista Tropos. 2016; 5(1).

17. SANCHEZ HM, et al. Impacto da saúde na qualidade de vida e trabalho de docentes universitários de diferentes áreas de conhecimento. Ciência e saúde coletiva, 2019; 24(11).

18. SANTANA FAL, NEVES IR. Saúde do trabalhador em educação: a gestão da saúde de professores de escolas públicas brasileiras. Saúde e Sociedade, 2017; 26(3): 786-797.

19. SANTOS CC, et al. Experiências da gestão acadêmica da docência universitária. Educação \& Realidade, 2013; 43(3).

20. SILVA AF, SOUZA ALL. Condições do trabalho escolar: desafios para os sistemas municipais de ensino. Cadernos de Pesquisa, 2013; 43(150): 772-787.

21. SOUZA NA, LEITE MP. Condições de trabalho e suas repercussões na saúde dos professores da educação básica no Brasil. Educação \& Realidade, 2011; 32(117).

22. VIANNA CP. O sexo e o gênero da docência. Cadernos pagu, 2002; 81-103.

23. ZIBETTI MLT, PEREIRA SR. Mulheres e professoras: repercussões da dupla jornada nas condições de vida e no trabalho docente. Educar em Revista, 2010; 2: 259-276. 